\title{
Physicians' Activities and Work Recommendations for Individuals with Chronic Low Back Pain: A comparison between Orthopedist and General Practitioners
}

\section{Saud M Al-Obaidi* and Nowall Al-Sayegh}

Department of Physical Therapy, Faculty of Allied Health Sciences, Kuwait University, Kuwait

\section{Abstract}

Background: Physicians are frequently asked to adjust the work or activities of patients with chronic low back pain (CLBP). These recommendations are influenced by physicians, their attitudes and beliefs about pain, and severity of patient's symptoms or pathology. Such recommendations may have significant impact on patients' physical therapy program. The purpose of this study was to explore physicians' activities and work recommendations for CLBP and to determine the predicting factors.

Methods: Questionnaires were mailed to 775 physician's in Kuwait (663 general practitioner (GPs) and 112 Orthopedic specialist (OS) ), inquiring about; Physicians demographics; age, gender, experience, education, interest in low back pain, as well as physician's rating of severity of symptoms and pathology for three CLBP vignettes, and recommendation for work and activities restrictions. Physician's pain attitudes and beliefs were assessed by the Health Care Provider Pain and impairment relationship scale (HC-PARIS).

Results: Of the 530 returned responses; $65 \%$ were GP'S and $91 \%$ were OS. GPs encountered more CLBP patients than OS. Most physicians recommended avoidance of work and painful activities or greater work restrictions. Although the GP's had high HC-PARIS, the OS were more restrictive in their recommendations. All physicians demonstrated consistence patterns of recommendations among the three vignettes. Significantly, physicians' pain attitudes and belief influenced their recommendations, as did their perception of the patients' clinical symptoms. Physicians' experience, interest in LBP, special education in LBP, total perception of severity of symptoms, and pathology, were significant independent predictors of the total work and activity recommendations.

Conclusions: Physicians' were not hesitant of restricting work or activities based on severity of symptoms and pathology for CLBP, regardless of their specialties, high or low HC-PAIRS scores.

\section{Introduction}

Chronic low back pain (CLBP) is a major health problem in Kuwait, with elevated lifetime and point prevalence rates [1,2], and accounts for the majority of physical therapist workload [1]. General Practitioner (GPs) and orthopedist specialists (OS), are the major referrals sources to physiotherapy services.

In some countries like Kuwait, physicians are exclusively authorized by the government bylaws to provide recommendations regarding work or activities restrictions. These recommendations are usually influenced by physicians own pain conceptualization, personal pain experiences and medical educational [3,4]. These beliefs may unintentionally be projected to the patients during clinical interviews, and reinforces pain avoidance behavior. [5] Restriction recommendations, specifically those related to physical activities and work, may undermine the objectives of physical therapy. Motivating an individual to perform an exercise, or return to work that he/ she was advised to avoid or restrict is quit challenging. Studying the nature of physician's beliefs and attitudes toward pain and their recommendations to restrict work or activities among various musculoskeletal problems is important to physical therapists.

The 'health care provider's pain and impairment relationship scale' (HC-PAIRs) was designed to evaluate physicians attitudes and beliefs about chronic pain [6,7], and to predict physicians work and activity recommendations $[4,7]$. The HC-PAIRs is a modified version of the pain and impairment relationship scale (PAIRS) designed by Riley et al., to explore patients own beliefs about CLBP [8]. The HC-PAIRS has demonstrated robust validity, internal consistency, and test-retest reliability $[4,6,7]$.

\section{Publication History:}

Received: September 05, 2014

Accepted: January 03, 2015

Published: January 05, 2015

\section{Keywords:}

Activities, Attitudes and beliefs, Chronic low back pain, Recommendations, Work

\section{Material and Methods}

Study questionnaire

The questionnaire was constructed based on the information reported by Rainville et al. [4]. The survey was mailed to all active orthopedic specialists (OS) and general practitioners (GPs) in the state of Kuwait. The questionnaires inquired about demographic characteristics: age, gender, specialty, years of experience $(<5$ years, 5-10 years, $>10$ years), interest in LBP (none, minimal, moderate, strong), special education in low back pain (none, fellowship/ continuing medical education courses (CME), and independent study) , average CLBP patients encounters per week, personal history with LBP (none, acute, chronic and recurrent) and personal experience with activity or work limitations (none, occasionally, always).

Included in the questionnaire were three clinical vignettes previously described by Raiville et al. [4], The vignettes differ in their pathology and work demands (Appendix 1). The pathology, symptoms, and work requirements were greatest in Vignette 1, followed by Vignette 3,

"Corresponding Author: Prof. Saud M. Al-Obaidi, Department of Physical Therapy, Faculty of Allied Health Sciences, Kuwait University, PO Box 31470 Sulaibikhat 90805, Kuwait, Tel: +965-24633-4880, Fax: +965-2463-3836; E-mail: dralobaidi@hsc.edu.kw

Citation: Al-Obaidi SM, Al-Sayegh N (2015) Physicians' Activities and Work Recommendations for Individuals with Chronic Low Back Pain: A comparison between Orthopedist and General Practitioners. Int J Phys Ther Rehab 1: 101. doi: http://dx.doi.org/10.15344/2455-7498/2015/101

Copyright: (C) 2015 Al-Obaidi et al. This is an open-access article distributed under the terms of the Creative Commons Attribution License, which permits unrestricted use, distribution, and reproduction in any medium, provided the original author and source are credited. 
Citation: Al-Obaidi SM, Al-Sayegh N (2015) Physicians' Activities and Work Recommendations for Individuals with Chronic Low Back Pain: A comparison between Orthopedist and General Practitioners. Int J Phys Ther Rehab 1: 101. doi: http://dx.doi.org/10.15344/2455-7498/2015/101

and least in Vignette 2. The vignettes purposely lacked diagnostic evidence of compression of neurologic structures or clear lesions that would justify surgical decompression [4]. All vignettes described patients who were out of work because of back pain.

Four independent 5-item rating scales were used to rate physician's opinion on the severity of symptoms, pathology, appropriate activity levels and work recommendations for each of the three vignettes. For severity of symptoms and severity of pathology, the scales graded responses were; 1-very mild, 2-mild, 3-moderate, 4-severe, or 5-extremely severe. For recommendations of appropriate activity levels, the graded responses were : 1-no activity limitations, 2- avoid only painful activities, 3 - limit activities to moderate exertion, 4- limit activities to light exertion, or 5- limit all physical activities. For the recommendations for appropriate work levels the graded responses were : 1-full time, full duty; 2 -full time, moderate duty; 3 -full time, light duty; 4-part time, light duty; or 5-remain out of work.

Physician's pain attitudes and beliefs about functional expectations were assessed utilizing the HC-PAIRS, which consisted of 15 statements on a 7-point Likert scale, ranging from 'totally disagree' (1) to 'totally agree' (7). The final score was totaled ranging from 15 justifies disability $[4,11]$.

\section{Survey procedure}

The questionnaire was sent to all OS and GPs working in the governmental hospitals and polyclinics. The GP's usually work at several outpatient polyclinics, while the OS work in specialized orthopedics hospitals, wards and receive referrals from GP's for secondary or tertiary care. Our participating physicians are of different ethnic backgrounds, and nationalities.

Five individuals were employed to deliver the survey envelopes to the target physicians. After three weeks, the heads of the orthopedic units and managers of the policlinic were reminded by a telephone call/visit to gather the physician's responses. The survey questionnaire distribution/collection ended after two months. To avoid any biases, both the identity of researchers and their addresses were not disclosed.

\section{Statistical methods}

Responses were manually entered into a database, characteristics of participant physicians were compared using independent sample t-test for interval data and chi square for nominal and ordinal data. One-way analysis of variance (ANOVA) and chi square for qualitative data were used . Chi-square was replaced by the Fisher's exact test if the assumptions underlying chi-square were violated. Pearson correlation was used to assess the association between two quantitative variables. The responses from each physician for all three vignettes for severity of symptoms, severity of pathology, work recommendations, and activity recommendations were totaled. The factors that influence the work and activity recommendations were assessed by multiple linear regression analyses using the sum of work and activity recommendation scores as dependent variables separately. The statistical significant p-value was set at 0.05 or less. Data analyses were performed using the Statistical Package for Social Sciences, v.17.0 (SPSS Inc., Chicago, USA).

\section{Results}

\section{Response rate} to 105. The higher HC-PAIRS score, the stronger the belief that CLBP

Of the 663 GPs and 112 OS employed physicians in the government sector, $530(68 \%)$ returned usable responses; 428 (65\%) were GPs and 102 OS (91\%).

\section{Sample characteristics}

Table 1 displays the demographic characteristics of participants and a comparison between GPs and OS. The participants of this study were of different age groups with almost half of the respondents being between the ages of 40 and 50 years. Significant statistical differences were found between OS and GPs in the following characteristics: approximately $71 \%$ of OS had more than 10 years of experience compared to $57 \%$ of GPs $(p=0.03)$. OS reported more interest in LBP and they were more likely to receive special education in LBP management $(\mathrm{p}<0.001)$. The GPs encountered more LBP patients per week than OS $(\mathrm{p}<0.001)$. While there were no differences found

\begin{tabular}{|c|c|c|c|c|}
\hline \multirow[t]{3}{*}{ Characteristics } & All & Orthopedists & GPs & P-value \\
\hline & $\mathrm{n}=530$ & $\mathrm{n}=102$ & $\mathrm{n}=428$ & \\
\hline & $\mathrm{n}(\%)$ & $\mathrm{n}(\%)$ & $\mathrm{n}(\%)$ & \\
\hline Age in years & & & & 0.656 \\
\hline$<40$ years & $183(34.5)$ & $33(32.4)$ & $150(35.0)$ & \\
\hline $40-50$ years & $249(47.0)$ & $47(46.1)$ & $202(47.2)$ & \\
\hline$>50$ years & $98(18.5)$ & $22(21.6)$ & $76(17.8)$ & \\
\hline Years of experience & & & & 0.031 \\
\hline$<5$ years & $55(10.4)$ & $6(5.9)$ & $49(11.4)$ & \\
\hline $5-10$ years & $160(30.2)$ & $24(23.5)$ & $136(31.8)$ & \\
\hline$>10$ years & $315(59.4)$ & $72(70.6)$ & $243(56.8)$ & \\
\hline Interest in low back pain & & & & $<0.001$ \\
\hline No & $293(55.3)$ & $2(2.0)$ & $291(68.0)$ & \\
\hline Minimal & $71(13.4)$ & $22(21.6)$ & $49(11.4)$ & \\
\hline Moderate & $123(23.2)$ & $57(55.9)$ & $66(15.4)$ & \\
\hline Strong & $43(8.1)$ & $21(20.6)$ & $22(5.1)$ & \\
\hline $\begin{array}{l}\text { Special education in low } \\
\text { back pain }\end{array}$ & & & & $<0.001$ \\
\hline None & $249(47.0)$ & $0(0.0)$ & $249(58.2)$ & \\
\hline CME Course/Fellowship & $224(42.3)$ & $78(76.5)$ & $146(34.1)$ & \\
\hline Independent study & $57(10.8)$ & $24(23.5)$ & $33(7.7)$ & \\
\hline $\begin{array}{l}\text { Average low back pain } \\
\text { patients per week }\end{array}$ & & & & $<0.001$ \\
\hline$<10$ & $132(24.9)$ & $41(40.2)$ & $91(21.3)$ & \\
\hline$\geq 10$ & $398(75.1)$ & $61(59.8)$ & $337(78.7)$ & \\
\hline $\begin{array}{l}\text { Personal history of low } \\
\text { back pain }\end{array}$ & & & & 0.239 \\
\hline None & $114(21.5)$ & $24(23.5)$ & $90(21.0)$ & \\
\hline Acute & 94(17.7) & $23(22.5)$ & $71(16.6)$ & \\
\hline $\begin{array}{l}\text { Chronic/ Recurrent } \\
\text { episodes }\end{array}$ & $322(60.8)$ & $55(53.9)$ & $267(62.4)$ & \\
\hline $\begin{array}{l}\text { Personal experience of } \\
\text { activity limitations }\end{array}$ & & & & $<0.001$ \\
\hline None & $247(46.6)$ & $34(33.3)$ & $213(49.8)$ & \\
\hline Occasionally & 201(37.9) & $57(55.9)$ & $144(33.6)$ & \\
\hline Always & $82(15.5)$ & $11(10.8)$ & 71(16.6) & \\
\hline $\begin{array}{l}\text { Table 1: Characteristics } \\
(\mathrm{n}=530) . \\
\mathrm{p} \text {-values are generated }\end{array}$ & $\begin{array}{l}\text { f surveyed } \\
\text { Chi-squar }\end{array}$ & $\begin{array}{l}\text { hysicians acc } \\
\text { test. }\end{array}$ & rding to $\mathrm{sp}$ & \\
\hline
\end{tabular}

Int J Phys Ther Rehab

ISSN: 2455-7498

IJPTR, an open access journal Volume 1. 2015. 101 
Citation: Al-Obaidi SM, Al-Sayegh N (2015) Physicians' Activities and Work Recommendations for Individuals with Chronic Low Back Pain: A comparison between Orthopedist and General Practitioners. Int J Phys Ther Rehab 1: 101. doi: http://dx.doi.org/10.15344/2455-7498/2015/101

Page 3 of 7

in personal experience of LBP between the two groups. OS reported experiencing more activity limitations associated with their personal experience of LBP than GPs ( $67 \%$ vs. $50 \%$ respectively; $p<0.001$ ).

\section{Responses to the vignettes}

Table 2 displays physicians' ratings of severity of symptoms, and pathology, as well as their recommendations for daily activity and work. The severity of symptoms and pathology of vignette 3 was higher than vignette 1 or vignette 2 , while vignette 1 received more recommendation for work and activity restrictions $(\mathrm{P}<.05$ to .001$)$. Vignette 2 was rated lowest on all items.

\section{Scores for HC-PAIRS}

Analysis of HC-PAIRS scores for all participating physicians revealed mean scores of $71.6 \pm 13.3$ with range scores between 41 to 105 indicating a wide range of opinion to justify functional impairments for CLBP, with the GP's having higher mean scores on HC-PAIRS than the OS $(72.5 \pm 9.7$ versus $67.7 \pm 9.7, \mathrm{p}=0.001)$.

\section{Factors affecting activity and work recommendations}

\section{Physician factors affecting activity and work recommendation}

To determine whether physicians recommendations were consistent

\begin{tabular}{|c|c|c|c|c|c|c|}
\hline & Vignette 1 & & Vignette 2 & Vignette 3 & & Total score \\
\hline & Mean \pm SD & & Mean \pm SD & Mean \pm SD & & Mean(SD) \\
\hline \multicolumn{7}{|l|}{ All Physicians } \\
\hline Severity of symptoms & $3.43 \pm 0.93$ & $* * *$ & $2.96 \pm 1.06$ & $3.60 \pm 1.06$ & $* * * \dagger$ & $9.99 \pm 1.66$ \\
\hline Severity of pathology & $3.28 \pm 1.01$ & $* * *$ & $2.65 \pm 0.99$ & $3.36 \pm 0.89$ & $* * *$ & $9.29 \pm 1.64$ \\
\hline Activity limitation & $3.13 \pm 1.27$ & $* * *$ & $2.76 \pm 1.04$ & $3.06 \pm 1.15$ & ** & $8.95 \pm 2.17$ \\
\hline Work recommendation & $3.46 \pm 1.19$ & $* * *$ & $2.62 \pm 1.24$ & $3.09 \pm 1.07$ & $* * * \dagger \dagger \dagger$ & $9.18 \pm 2.25$ \\
\hline
\end{tabular}

Table 2: Responses of items following patient vignettes for surveyed physicians $(n=530)$.

Total score $=$ Combined score for each physician for all three vignettes; $\mathrm{SD}=$ standard deviation

$\mathrm{p}$-values are generated by paired t-test. ${ }^{\star} \mathrm{p}<0.05,{ }^{* *} \mathrm{p}<0.01,{ }^{* * *} \mathrm{p}<0.001$ Vignette 1,3 versus Vignette $2 ; \dagger \mathrm{p}<0.05, \dagger \dagger \mathrm{p}<0.01, \dagger \dagger \dagger \mathrm{p}<0.001$, Vignette 1 versus 3 .

\section{Comparison between orthopedic and general practitioners}

Figure 1 illustrates the mean and standard deviations of the differences between OS and GPs ratings of the severity of symptoms, pathology, and for activities and work recommendations across the three vignettes. Both the OS and the GP's gave high rating to the severity of symptoms of vignette $3(3.66 \pm .84$ and $3.58 \pm 1.10)$ but without significant differences $\mathrm{P}<0.44$. The OS had more rating for symptom severity $(3.62 \pm 0.77$ vs $3.39 \pm 0.96, \mathrm{p}=0.012)$, and more restriction for work recommendations $(3.69 \pm 1.05$ vs $3.41 \pm 1.21$, $\mathrm{p}=0.021)$ than GP for patients in vignette 1 . Moreover, OS had a higher rating of activity $(3.72 \pm 0.45$ vs $2.91 \pm 1.21, \mathrm{p}<0.001)$ and work restriction $(4.33 \pm 0.57$ vs $2.79 \pm 0.94, \mathrm{p}<0.001)$ than GPs for patients in vignette 3 . There was no difference between the OS and GPs on activity limitations for Vignette 1 and for work recommendation for vignette 2 . The GPs demonstrated more activity restriction than OS for patients in vignette $2(2.86 \pm 1.04$ vs $2.34 \pm 0.93, \mathrm{p}<0.001)$. or random, the activities and work recommendations of all physicians were combined and totaled and a correlation matrix for physicians activities and work recommendations within and between vignettes were constructed (Table 3). Significant correlations were found among most activity and work recommendations within and between vignettes, reflecting on the consistency of physicians recommendations despite the differences in the clinical presentation, activity and work demands.

The physicians HC-PAIRS were significantly correlated with work and activity recommendations in vignette 2 (work $\mathrm{r}=0.348, \mathrm{p}<0.001$; activity $\mathrm{r}=0.175, \mathrm{p}<0.001$ ) and vignette 3 (work $\mathrm{r}=-0.153, \mathrm{p}<0.001$; activity $\mathrm{r}=-0.164, \mathrm{p}<0.001$ ), but not for vignette 1 .

Physician's work recommendations were also influenced by physician's perceptions of the severity of symptoms and pathology. Severity of symptoms was correlated with work recommendations as follow: for vignette $1 \quad(\mathrm{r}=0.529, \mathrm{p}<0.001)$ for vignette 2
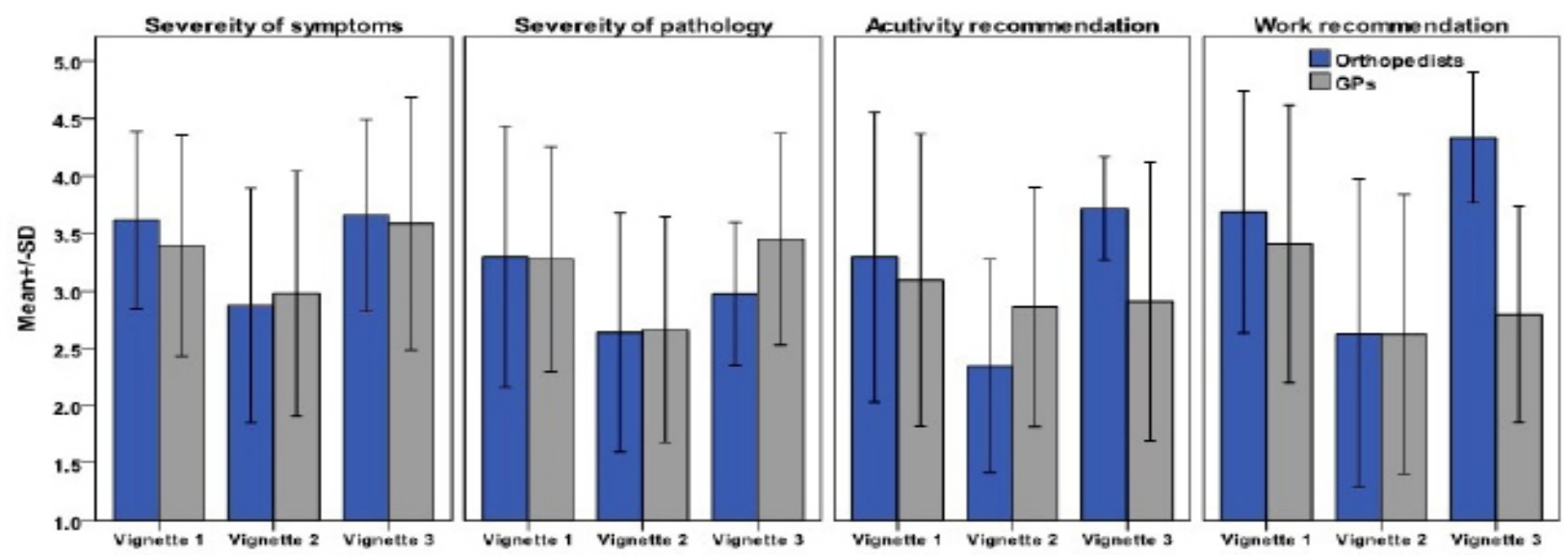

Figure 1: Comparison of Means and Standard deviations between Orthopedics and General Practioners on severity of symptoms, pathology, activities and work recommendations across vignettes. 
Citation: Al-Obaidi SM, Al-Sayegh N (2015) Physicians' Activities and Work Recommendations for Individuals with Chronic Low Back Pain: A comparison between Orthopedist and General Practitioners. Int J Phys Ther Rehab 1: 101. doi: http://dx.doi.org/10.15344/2455-7498/2015/101

\begin{tabular}{|c|c|c|c|c|c|c|c|c|c|c|c|c|}
\hline & \multicolumn{4}{|c|}{ Vignette 1} & \multicolumn{4}{|c|}{ Vignette 2} & \multicolumn{4}{|c|}{ Vignette 3} \\
\hline & \multicolumn{2}{|c|}{ Activities } & \multicolumn{2}{|c|}{ Work } & \multicolumn{2}{|c|}{ Activities } & \multicolumn{2}{|c|}{ Work } & \multicolumn{2}{|c|}{ Activities } & \multicolumn{2}{|c|}{ Work } \\
\hline & $\mathrm{r}$ & $\mathrm{p}$-value & $\mathrm{r}$ & p-value & $\mathrm{r}$ & p-value & $\mathrm{r}$ & p-value & $\mathrm{r}$ & $\mathrm{p}$-value & $\mathrm{r}$ & $\mathrm{p}$-value \\
\hline \multicolumn{13}{|l|}{ Vignette 1} \\
\hline \multicolumn{13}{|l|}{ Activities } \\
\hline Work & 0.364 & $<0.001$ & & & & & & & & & & \\
\hline \multicolumn{13}{|l|}{ Vignette 2} \\
\hline Activities & 0.211 & $<0.001$ & 0.038 & 0.387 & & & & & & & & \\
\hline Work & 0.151 & $<0.001$ & 0.262 & $<0.001$ & 0.363 & $<0.001$ & & & & & & \\
\hline \multicolumn{13}{|l|}{ Vignette 3} \\
\hline Activities & 0.101 & 0.019 & 0.131 & 0.003 & -0.007 & 0.877 & -0.079 & 0.071 & & & & \\
\hline Work & 0.115 & 0.008 & 0.131 & 0.003 & 0.200 & $<0.001$ & -0.050 & 0.254 & 0.668 & $<0.001$ & & \\
\hline
\end{tabular}

Table 3: Correlation matrix for physicians' activity and work recommendations within and between patient vignettes ( $\mathrm{n}=530$ ).

$\mathrm{r}=$ Pearson correlation coefficient.

$(\mathrm{r}=0.416, \mathrm{p}<0.001)$ and vignette $3(\mathrm{r}=-0.117, \mathrm{p}=0.007)$ and for total work recommendation $(r=0.350, p<0.001)$. Severity of pathology was correlated with work recommendation as follows: vignette $1(\mathrm{r}=0.485$, $\mathrm{p}<0.001)$ vignette $2(\mathrm{r}=0.497, \mathrm{p}<0.001)$ vignette $3(\mathrm{r}=-0.157, \mathrm{p}=0.007)$ for total work recommendation $(\mathrm{r}=0.289, \mathrm{p}<0.001)$.

Physician's activity recommendations were also influenced by physician's perceptions of the severity of symptoms and pathology. Severity of symptoms was correlated with activity recommendations as follows: for vignette $1(\mathrm{r}=0.220, \mathrm{p}<0.001)$, vignette $2(\mathrm{r}=0.818, \mathrm{p}<0.001)$, vignette $3(\mathrm{r}=-0.086, \mathrm{p}=0.047)$ and for total work recommendation $(\mathrm{r}=0.403, \mathrm{p}<0.001)$. Severity of pathology was correlated with activity recommendation as follows: Vignette $1(\mathrm{r}=0.302, \mathrm{p}<0.001)$, vignette $2(\mathrm{r}=0.444, \mathrm{p}<0.001)$, vignette $3(\mathrm{r}=-0.018, \mathrm{p}=0.680)$ and for total activity recommendation $(\mathrm{r}=0.289, \mathrm{p}<0.001)$.

Table 4 explores the differences between physician's characteristics and their recommendations for activity and work. Neither the age of physicians nor the numbers of years of experience were related to activity or work recommendations. Special education and interest in CLBP related significantly to works and activities restriction. Physicians who encounter more patients per week tended to be less restrictive on work but more on activity restriction. Physicians' personal experience with CLBP correlated significantly with less restriction for activity, while a physician who personally experienced activity limitation due to LBP tended to be more restrictive of his/her activity recommendations. Physicians' personal experience of CLBP did not relate to work recommendations.

\section{Patient factors affecting activities and work recommendations}

Physicians rated the severity of symptoms and pathology as more severe in vignettes 3 followed by vignettes 1 and least in vignette 2 $(\mathrm{P}<0.001)$ (Table 2). On the other hand, physician recommendations for work and activity demonstrated that activities and work were more restricted for vignette 1 than vignette 3 and least for vignette 2 . However, this was unexpected and contrary to the given information in the case scenario presented in each vignette, as symptoms and pathology were made intentionally worse in vignette 1 and vignette 3 .

\section{Predictors of activities and work recommendations}

The multiple linear regression analysis revealed that physicians' experience, interest in LBP, special education in LBP, totaled perception of severity of symptoms, and pathology, were significant independent predictors of the totaled activity recommendations. Similarly significant independent predictors of work recommendations were: specialty, special education in LBP, totaled perception of severity of symptoms, pathology, and HC-PAIRS scores (table 5).

The strongest predictors were ratings of severity of symptoms and pathology along with physicians' specialty. The negative regression coefficient related to specialty indicated that OSs were more than twice as likely to restrict work as GPs.

\section{Discussion}

The response rate of this survey was excellent given the total number of OS and GPs physicians working in Kuwait. The OS response rate was high (91\%) and may have been because the majority of OSs were located in one large specialized orthopedic hospital, while the GPs $(65 \%)$ worked at various policlinics in the metropolitan area.

The result showed that although GPs encountered more LBP than the OSs, the majority (58.2\%) had no interest in CLBP, and only $36.8 \%$ of GPs had continuing education in CLBP. Given the high prevalence rate of LBP in Kuwait [1], the GPs may benefit from special education and guideline reviews for the management of CLBP.

The results demonstrate a wide range of physician's opinions regarding rating the severity of symptoms and pathology as well as for activities and work recommendations for each vignette. Although vignette 1 was intentionally made worse in symptoms, pathology, activities and work demands than vignette 3 or vignette 2 [4], all physicians had rated the severity and pathology as most severe for vignette 3 than Vignette 1 and all agreed that vignette 2 was the least. However, contrary to their ratings of the severity of symptoms and pathology, all physicians recommended restriction of activity and work more to vignette 1 than vignette 3 and all agreed for less restriction for vignette 2 . 
Citation: Al-Obaidi SM, Al-Sayegh N (2015) Physicians' Activities and Work Recommendations for Individuals with Chronic Low Back Pain: A comparison between Orthopedist and General Practitioners. Int J Phys Ther Rehab 1: 101. doi: http://dx.doi.org/10.15344/2455-7498/2015/101

Page 5 of 7

\begin{tabular}{|c|c|c|c|c|c|c|}
\hline \multirow{2}{*}{ Age in years } & \multicolumn{3}{|c|}{ Activity recommendation } & \multicolumn{3}{|c|}{ Work recommendation } \\
\hline & \multicolumn{2}{|c|}{ Mean(SD) } & $\frac{p \text {-value }}{0.942^{\mathrm{b}}}$ & \multicolumn{2}{|c|}{ Mean(SD) } & $\frac{\mathrm{p} \text {-value }}{0.850^{\mathrm{b}}}$ \\
\hline$<40$ years & 9.04 & $(2.57)$ & & 9.10 & $(2.48)$ & \\
\hline $40-50$ years & 8.96 & $(2.39)$ & & 9.23 & $(2.13)$ & \\
\hline$>50$ years & 9.02 & $(2.35)$ & & 9.17 & $(2.11)$ & \\
\hline Experience in years & & & $0.579^{b}$ & & & $0.411^{\mathrm{b}}$ \\
\hline$<5$ years & 9.09 & $(2.29)$ & & 8.85 & $(2.12)$ & \\
\hline 5-10 years & 9.15 & $(2.57)$ & & 9.32 & $(2.48)$ & \\
\hline$>10$ years & 8.91 & $(2.40)$ & & 9.16 & $(2.15)$ & \\
\hline Interest in low back pain & & & $<0.001^{\mathrm{b}}$ & & & $<0.001^{\mathrm{b}}$ \\
\hline No & 8.30 & $(2.33)$ & & 8.60 & $(2.20)$ & \\
\hline Minimal & 9.68 & $(2.42)$ & & 10.10 & $(2.18)$ & \\
\hline Moderate & 9.78 & $(2.31)$ & & 9.62 & $(1.95)$ & \\
\hline Strong & 10.42 & $(2.01)$ & & 10.28 & $(2.39)$ & \\
\hline Special education in low back pain & & & $<0.001^{\mathrm{b}}$ & & & $0.041^{\mathrm{b}}$ \\
\hline None & 8.56 & $(2.16)$ & & 8.93 & $(2.18)$ & \\
\hline CME Course/Fellowship & 9.44 & $(2.61)$ & & 9.46 & $(2.31)$ & \\
\hline Independent study & 9.21 & $(2.59)$ & & 9.14 & $(2.21)$ & \\
\hline Average low back pain patients per week & & & $0.141^{\mathrm{a}}$ & & & $0.026^{\mathrm{a}}$ \\
\hline$<10$ & 9.27 & $(2.48)$ & & 9.55 & $(2.09)$ & \\
\hline$\geq 10$ & 8.91 & $(2.43)$ & & 9.05 & $(2.29)$ & \\
\hline Personal history of low back pain & & & $0.003^{\mathrm{b}}$ & & & $0.504^{\mathrm{b}}$ \\
\hline None & 9.18 & $(2.12)$ & & 9.25 & $(2.16)$ & \\
\hline Acute & 9.68 & $(2.26)$ & & 9.38 & $(1.97)$ & \\
\hline Chronic/ Recurrent episodes & 8.74 & $(2.56)$ & & 9.09 & $(2.36)$ & \\
\hline Personal experience of activity limitations & & & $0.019^{b}$ & & & $0.796^{\mathrm{b}}$ \\
\hline None & 8.73 & $(2.31)$ & & 9.13 & $(2.21)$ & \\
\hline Occasionally & 9.10 & $(2.60)$ & & 9.26 & $(2.31)$ & \\
\hline Always & 9.57 & $(2.31)$ & & 9.10 & $(2.24)$ & \\
\hline
\end{tabular}

Table 4: Comparison of activity and work recommendation total scores by characteristics of surveyed physicians $(\mathrm{n}=530)$. p-values are generated by ${ }^{a}$ Student t-test and ${ }^{\mathrm{b}}$ one-way ANOVA.

\begin{tabular}{|l|l|l|l|l|}
\hline \multirow{2}{*}{} & \multicolumn{3}{|l|}{ Activity recommendation total score } & \multicolumn{2}{l|}{ Work recommendation total score } \\
\cline { 2 - 5 } & Coefficient & p-value & Coefficient & p-value \\
\hline Age in years & 0.016 & 0.203 & -0.005 & 0.667 \\
\hline Experience in years & -0.374 & 0.012 & 0.038 & 0.798 \\
\hline Interest in low back pain & 0.363 & $<0.001$ & 0.177 & 0.059 \\
\hline Special education in low back pain & -0.296 & 0.001 & -0.396 & $<0.001$ \\
\hline Personal history of low back pain & 0.127 & 0.275 & -0.112 & 0.333 \\
\hline Personal experience of activity limitations & -0.121 & 0.239 & -0.056 & 0.582 \\
\hline HC-PAIRS scores & 0.005 & 0.440 & 0.024 & $<0.001$ \\
\hline Severity of symptoms total score & 0.461 & $<0.001$ & 0.359 & $<0.001$ \\
\hline Severity of pathology total score & 0.211 & $<0.001$ & 0.311 & $<0.001$ \\
\hline Specialty & -0.442 & 0.119 & -2.28 & $<0.001$ \\
\hline
\end{tabular}

Table 5: Comparison of activity and work recommendation total scores by characteristics of surveyed physicians $(\mathrm{n}=530)$. 
Citation: Al-Obaidi SM, Al-Sayegh N (2015) Physicians' Activities and Work Recommendations for Individuals with Chronic Low Back Pain: A comparison between Orthopedist and General Practitioners. Int J Phys Ther Rehab 1: 101. doi: http://dx.doi.org/10.15344/2455-7498/2015/101

A comparison between the two groups showed that the GPs and OSs did not differ significantly in rating the severity of symptoms in Vignette 2 and 3 and severity of pathology in vignette 1 and 2 . The severity of symptoms of vignette 1 was rated more by OS, than GPs with minor significant differences regarding work recommendation. The pathology of vignette 3 received a high rating by the GPs, without significant restrictive recommendation for work or activities.

The HC-PAIRS mean scores of all physicians was high reflecting strong willingness to justify functional impairment for CLBP, with the GPs having higher HC-PAIRS scores than the OSs. This indicates that GPS are more liberal in prescribing activity and work restriction.

However, comparison of the responses of OSs and GPs across different vignettes showed that the OSs were more restrictive of work and activities than GPS, specifically to vignette 1 and vignette 3 (Figur 1). Our findings contradict those of Rainville and colleagues who reported that orthopedic specialists were less restrictive than family physicians [4].

Although we used an English version of the HC-PARIS with its high validly scores, we found contradiction between the HC-PARIS scores and their relationships to work and activity recommendations; i.e. the GPs who have high HC-PARIS scores were less restrictive for work and activity while the OSs who have relatively less HC-PARIS scores had more restrictive recommendations.

CLBP is a complex medical problem with diverse psychosocial aspect[21]. It may be that the presented clinical information was not sufficient for some physicians, or that the hypothetical vignette could not substitute a real patient encounter with all of its clinical correlations and clear visual cues.

Clinicians may need to comprehensively explore patient symptoms, physically examine the patients, read the laboratory and radiographic investigations, and explore the activities and work demands directly with the patients prior to giving sound clinical judgment [6].

Other transient factors such as physicians' optimism, mood, and fatigue tend to influence the physicians' opinion than recommendations that are based solely on medical science. We also believe that the validity of the HC-PAIRS although established in western society, cross cultural differences in cultural values, traditions, practice, ethnicity and religious beliefs may have influenced physician's recommendations in this part of the world. It has been reported that ethnicity and cultural background can influence an individual's beliefs and attitudes towards LBP [26-28].

Physician's factors such as pain attitude and belief as measured by HC-PAIRS were significantly correlated with work and activity recommendations in vignette 2 and vignette 3 but not with vignette 1. This study demonstrated that both severity of symptoms and pathology influenced physicians' recommendation on work and activities. Physician's recommendations for activity correlated significantly with severity of symptoms and pathology more in vignette 1 for symptom severity and with vignette 2 for pathology and least for vignette 3. Physician recommendations for activity was also correlated with severity of symptoms and pathology more for vignette 2 and vignette 1 only. This was contrary to our expectations that all physicians regardless of their specialty would have identified vignette 1 as more severe in symptoms and pathology and therefore recommend appropriate work and activity limitations.
Our findings may also reflect physician's beliefs and attitudes concerning the significance of CLBP observed in this part of the world regardless of their medical knowledge and present management guidelines. Because the patients factors investigated in this study were restricted to only severity of symptoms and uncomplicated pathology, we postulate that if the symptoms and pathology scenarios were made more complicated than they are the influence on work and activity restriction can be even exaggerated.

Our findings indicate that physicians involved in this study were not hesitant of restricting work or activities based on severity of symptoms and pathology of CLBP. This was regardless of high or low HC-PAIRS scores were. Our findings are in agreement with other studies linking physicians' recommendations to their pain attitudes and beliefs. [4,6,16,28,29].

The results of the multiple linear regression analysis revealed that factors such as physicians' years of experience, interest in LBP, special education in LBP, totaled perception of severity of symptoms and severity of pathology, were robust predictors of activity recommendations. Contrary to the findings of Rainville and colleagues, our findings did not find the HC-PAIRS as a strong predictor of activity limitations. $[4,6]$ The independent predictors of work recommendations were; physician specialty, special education in LBP, totaled perception of severity of symptoms, pathology, and least to the HC-PAIRS scores.

Our findings however are in agreement with Rainville et al who indicated that physicians' personal experience with back pain did not alter their work or activity recommendations [4], while Haldorsen et al found that physicians' personal experience with LBP had strong influence on their recommendations [16]. We did not find any influence of age and number of patients seen per week on physician's work or activity recommendations which was in agreement with reports in previous studies. $[4,16]$.

\section{Conclusion}

Physician's were not hesitant of restricting work or activities based on severity of symptoms and pathology for CLBP, regardless of their high or low HC-PAIRS scores. Physicians' age, personal experience or back pain did not alter their recommendations. Physicians years of experience, personal interest and special education in low back pain, appears to influence their activity or work recommendations. General practitioners although had high HC-PAIRS, it was the orthopedic specialist whom were more restrictive of work and activities.

\section{Authors contribution}

Saud Al-Obaidi: conception, design, interpretation of data, drafting of manuscript.

Nowall Al-Sayegh: drafting and editing of manuscript, analysis and interpretation of data, revising manuscript for intellectual content.

\section{Acknowledgements}

This project was partially funded by Kuwait University Research Sector. 
Citation: Al-Obaidi SM, Al-Sayegh N (2015) Physicians' Activities and Work Recommendations for Individuals with Chronic Low Back Pain: A comparison between Orthopedist and General Practitioners. Int J Phys Ther Rehab 1: 101. doi: http://dx.doi.org/10.15344/2455-7498/2015/101

\section{References}

1. Landry, MD, Raman SR, Sulway C, Golightly YM, Hamdan E (2008) Prevalence and risk factors associated with low back pain among health care providers in a Kuwait Hospital. Spine 33: 539-545.

2. Shehab DK, Al-Jarallah KF (2005) Nonspecific low-back pain in Kuwaiti children and adolescents: Associated factors. J Adolescent HIth 36: 32-35.

3. Bishop A, Foster NE, Thomas E, Hay EM (2008) How does the selfreported clinical management of patients with low back pain relate to the attitudes and beliefs of health care practitioners? A survey of UK general practitioners and physiotherapists. Pain 135: 187-195.

4. Rainville J, Carlson N, Polatin P, Gatchel RJ, Indahl A (2000) Exploration of physicians' recommendations for activities in chronic low back pain. Spine 25: $2210-2220$

5. Waddell G, Newton M, Henderson I, Somerville D, Main CJ (1995) A FearAvoidance Beliefs Questionnaire (FABQ) and the role of fear-avoidance beliefs in chronic low back pain and disability. Pain 52: 157-168

6. Rainville J, Bagnall D, Phalen L (1995) Health care providers' attitudes and beliefs about functional impairments and chronic back pain. Clin J Pain 11: 287-295.

7. Houben RM, Gijsen A, Peterson J, De Jong PJ, Vlaeyen JW (2005) Do health care providers' attitudes towards back pain predict their treatment recommendations? Differential predictive validity of implicit and explicit attitude measures. Pain 114: 491-498.

8. Riley JF, Ahern DK, Follick MJ (1988) Chronic pain and functional impairment: assessing beliefs about their relationship. Arch Phys Med Rehabil, 69: 579-82.

9. Cherkin DC, MacCornack FA, Berg AO (1988) Managing low back pain - A comparison of the beliefs and behaviors of family physicians and chiropractors. Western J Med 149: 475-480.

10. Cherkin DC, Deyo RA, Wheeler K, Ciol MA, Carey T (1995) Physician views about treating low back pain: The results of a national survey. Spine 20: $1-10$.

11. Houben RMA, Vlaeyen JWS, Peters M, Ostelo RWJG, Wolters PMJC, et al (2004) Health Care Providers' Attitudes and Beliefs Towards Common Low Back Pain: Factor Structure and Psychometric Properties of the HC-PAIRS. Clin J Pain 20: 37-44

12. Turk DC, Brody MC, Okifuji EA (1994) Physicians' attitudes and practices regarding the long-term prescribing of opioids for non-cancer pain. Pain 59: 201-208

13. Von Korff M, Barlow W, Cherkin D, Deyo RA (1994) Effects of practice style in managing back pain. Ann Intern Med 121: 187-195.

14. Carey TS, Hadler NM, Gillings D, Stinnett S, Wallsten T (1988) Medical disability assessment of the back pain patient for the social security administration: The weighting of presenting clinical features. J Clin Epidemiol 41: 691-697.

15. Chibnall JT, Dabney A, Tait RC (2000) Internist Judgments of Chronic Low Back Pain. Pain Med $1: 231-237$

16. Haldorsen EMH, Brage S, Johannesen TS, Tellnes G, Ursin H (1996) Musculoskeletal pain: Concepts of disease, illness, and sickness certification in health professionals in Norway. Scand J Rheumatol 25: 224 232.

17. Patel B, Buschbacher R, Crawford J (2003) National variability in permanent partial impairment ratings. Am J Phys Med Rehabil 82: 302-306.

18. Coudeyre E, Rannou F, Tubach F, Baron G, Coriat F, et al. (2006) General practitioners' fear-avoidance beliefs influence their management of patients with low back pain. Pain 124: 330-337.

19. Daykin, AR. Richardson B (2004) Physiotherapists' Pain Beliefs and Their Influence on the Management of Patients with Chronic Low Back Pain. Spine 29: 783-795

20. Linton SJ, Vlaeyen J, Ostelo R (2002) The back pain beliefs of health care providers: Are we fear-avoidant? J Occup Rehabil 12: 223-232.
22. Waddell G (2004) The Back Pain Revolution, 2nd ed. Edinburgh, Churchill Livingstone.

23. Spitzer W, LeBlanc F, Dupuis M (1987) Scientific approach to the assessment and management of activity-related spinal disorders. A monograph for clinicians. Report of the Quebec Task Force on Spinal Disorders. Spine 12: S1-S59.

24. Clinical Standards Advisory Group (1994) Report on Back Pain HMSO London.

25. Deyo RA, Diehl AK, Rosenthal M (1986) How many days of bed rest for acute low back pain? A randomized clinical trial. New England J Med 315: 1064-1070.

26. Lawrence VA, Tugwell P, Gafni A, Kosuwon W, Spitzer WO (1992) Acute low back pain and economics of therapy: The iterative loop approach. J Clin Epidemiol 45: 301-311.

27. Bates MS, Edwards WT, Anderson KO (1993) Ethnocultural influences on variation in chronic pain perception. Pain 52: 101-112.

28. Sanders SH, Brena SF, Spier CJ, Beltrutti D, McConnell H, et al. (1992) Chronic low back pain patients around the world: Cross-cultural similarities and differences. Clin J Pain 8: 317-323.

29. Tait R, DeGood D, Carron H (1982) A comparison of health locus of control beliefs in low-back patients from the U.S. and New Zealand. Pain 14: 5361.

30. Monday J, Therrien S, Duguay M, Lapierre G (1988) The physician and disability certification: Preconceived attitudes and behaviors. Canad J Psychiat 33: 599-605 